\title{
Molecular-biology and structural study of Avian orthoreovirus non-structural proteins
}

\author{
B. Kascakova1' Z. Franta1 , Z. Gardian¹, 2, I. Kuta Smatanova1, R. Tuma1,3 \\ ${ }^{1}$ University of South Bohemia, Faculty of Science, Branisovska 1760, CZ-37005 Ceske Budejovice, Czech Republic, \\ ${ }^{2}$ Laboratory of electron Microscopy, Biology Centre CAS, Branisovska 1160/31, CZ-37005 Ceske Budejovice, Czech Republic, \\ ${ }^{3}$ University of Leeds, School of Molecular and Cellular Biology, The Astbury Centre for Structural Molecular Biology, Leeds LS2 9JT, \\ $U K$ \\ rtuma@prf.jcu.cz
}

The fusogenic avian Orthoreovirus (ARV) infection can cause considerable economic losses in the poultry industry, mostly infecting young chickens. The ARV has been associated with various disease conditions in poultry (enteric and respiratory diseases, myocarditis, hepatitis, stunting-malabsorption syndrome, and the most important one viral arthritis/tenosynovitis) [1]. The ARV are non-enveloped icosahedral particles of $85 \mathrm{~nm}$ external diameter with 10 dsRNA genomic segments $(23.5 \mathrm{~kb})$ encased within two concentric protein shells, forming the outer capsid and the core [2].

Reoviruses' RNA replication and morphogenesis occur exclusively within cytoplasmic inclusion bodies, also known as 'viroplasms' or viral factories (VF). VF are globular, dynamic, phase-dense, cytoplasmic inclusions lacking membranes or cellular organelles. VFs are formed by abundant viral non-structural (NS) proteins and structural proteins recruited into VF by interaction with NS proteins. NS proteins are expressed inside the infected cells but are not part of the mature virion. The two most abundant VF proteins are $\mu$ NS and $\sigma \mathrm{NS} . \mu \mathrm{NS}$ is a $70 \mathrm{kDa}$ protein that is forming viroplasm inside infected cells and attracts and associates with other viral proteins including $41 \mathrm{kDa}$ RNA chaperone $\sigma \mathrm{NS}$ [3]. $\sigma \mathrm{NS}$ is causing specific RNA-RNA interaction between all 10 genomic segments specifically by destabilizing of RNAs helical regions [4]. There is missing information about a fashion of coupling of $\mu$ NS with $\sigma \mathrm{NS}$ protein needed for the understanding of viroplasm formation mechanism.

Only a low-resolution structure of $\sigma \mathrm{NS}$ has been established while no structural information is available for $\mu$ NS. This is chiefly due to the poor solubility of $\mu \mathrm{NS}$ and polydispersity of $\sigma \mathrm{NS}$ which forms oligomers ranging dimers to octamers and RNA containing filaments [4]. To tackle these problems and obtain structural information we have generated various fusion constructs for expression, purification, and further structural study by X-ray crystallography and electron cryo-microscopy. Due to their multi-facet role in virus biology, the detailed knowledge of their structure is necessary for a better understanding of their functions and could provide the rationale for the development of new antiviral drugs.

[1] Jones R. C. (2000). Revue scientifique et technique (International Office of Epizootics), 19(2), 614-625. https://doi.org/10.20506/rst.19.2.1237.

[2] Zhang, X., Tang, J., Walker, S. B., O'Hara, D., Nibert, M. L., Duncan, R., \& Baker, T. S. (2005). Virology, 343(1), 25-35. https://doi.org/10.1016/j.virol.2005.08.002.

[3] Benavente, J., \& Martínez-Costas, J. (2007). Virus research, 123(2), 105-119. https://doi.org/10.1016/j.virusres.2006.09.005.

[4] Borodavka, A., Ault, J., Stockley, P. G., \& Tuma, R. (2015). Nucleic acids research, 43(14), 7044-7057. https://doi.org/10.1093/nar/gkv639.

Keywords: non-structural proteins; avian Orthoreovirus; $\sigma \mathrm{NS} ; \mu \mathrm{NS}$; viroplasm

This research is supported by ERDF No. CZ.02.1.01/0.0/0.0/15_003/000041 and GAJU 04-017/2019/P. 